\title{
Flexible and Transparent Plastic Electrodes Composed of Reduced Graphene Oxide/Polyaniline Films for Supercapacitor Application
}

\author{
Ashis K. Sarker and Jong-Dal Hong* \\ Department of Chemistry, Incheon National University, Incheon 406-772, Korea. *E-mail: hong5506@incheon.ac.kr \\ Received January 29, 2014, Accepted February 28, 2014
}

\begin{abstract}
In this article, we described about the preparation and electrochemical properties of a flexible energy storage system based on a plastic polyethylene terephthalate (PET) substrate. The PET treated with UV/ozone was fabricated with multilayer films composed of 30 polyaniline (PANi)/graphene oxide (GO) bilayers using layerby-layer assembly of positively charged PANi and negatively charged GO. The conversion of GO to the reduced graphene oxide (RGO) in the multilayer film was achieved using hydroiodic acid vapor at $100{ }^{\circ} \mathrm{C}$, whereby PANi structure remained nearly unchanged except a little reduction of doping state. Cyclic voltammetry and charge/discharge curves of $30 \mathrm{PANi} / \mathrm{RGO}$ bilayers on PET substrate (shorten to PANi$\mathrm{RGO}_{30} / \mathrm{PET}$ ) exhibited an excellent volumetric capacitance, good cycling stability, and rapid charge/discharge rates despite no use of any metal current collectors. The specific capacitance from charge/discharge curve of the PANi-RGO $30 / \mathrm{PET}$ electrode was found to be $529 \mathrm{~F} / \mathrm{cm}^{3}$ at a current density of $3 \mathrm{~A} / \mathrm{cm}^{3}$, which is one of the best values yet achieved among carbon-based materials including conducting polymers. Furthermore, the intrinsic electrical resistance of the PANi-RGO ${ }_{30} / \mathrm{PET}$ electrodes varied within $20 \%$ range during 200 bending cycles at a fixed bend radius of $2.2 \mathrm{~mm}$, indicating the increase in their flexibility by a factor of 225 compared with the ITO/PET electrode.
\end{abstract}

Key Words : Reduced graphene oxide, Polyaniline, Flexibility, Conductivity, Supercapacitor

\section{Introduction}

Currently, development of flexible and bendable energy storage devices has received strong attention in order to meet the next-generation electronic equipment including rollup displays and wearable devices. ${ }^{1}$ Fabrication of bendable power sources is a major challenge due to a lack of reliable materials that combine electronically superior conductivity, high mechanical flexibility, and high stability in electrochemical environments. Over the past few years, carbon materials mixed with metal oxide and conducting polymers have been widely studied in supercapacitors. Supercapacitors are very attractive power sources, because their recharge times are generally short, they yield long life cycle, and high power. Graphene which is an emerging carbon material consisting of monolayered $s p^{2}$ hybird carbon atom, has been a hot topic for the use in flexible supercapacitor application owing to the good electronic conductivity, corrosion resistance in aqueous electrolyte and high mechanical elasticity. ${ }^{2-5}$ Recently, conducting polymers including polyaniline (PANi), polypyrrole, polythiophene have been combined into graphene-based supercapacitors for the enhancement of total capacitance via an additional contribution of pseudocapacitance. ${ }^{6-9}$ Among the conducting polymers, PANi has been considered as one of the most promising electrode material due to its high flexibility and relatively high conductivity. ${ }^{10}$ A large variety of composite materials including graphene and PANi has been developed for the supercapacitor application, i.e. graphene/PANi composite, ${ }^{11}$ graphene/PANi nanofiber composite, ${ }^{12}$ electrochemically polymerized $\mathrm{PANi} /$ reduced graphene oxide (RGO) films, ${ }^{13}$ PANi nanorods array on graphene oxide (GO) nanosheets, ${ }^{14}$ graphene/PANi porous silica MCM-41, ${ }^{15}$ and PANi-coated curved graphene active materials. ${ }^{16}$ However, a challenging task still remains for development of flexible transparent lightweight supercapacitors with high power and energy density based on PANi/ RGO film electrodes on a plastic substrates including polyethylene terephthalate (PET).

In this article, we report about a plastic-based supercapacitor fabricated with thin PANi/RGO films using layer-bylayer (LBL) deposition method, ${ }^{17}$ which allows fine-tuning of morphology, thickness, and electric conductivity of the electrode material. The electrochemical properties of the plastic supercapacitor were evaluated using cyclic voltammetry $(\mathrm{CV})$ and charge/discharge curves. We also investigated the stability in the electrical resistance of the PANi/ RGO film on PET as a function of bending angle and cycles in comparison with indium tin oxide (ITO)/PET substrates.

\section{Experimental Section}

Materials. Natural graphite powder (particle size $<20$ $\mu \mathrm{m}, 99.99 \%$ ), PANi in emeraldine base form (MW 50 000), and hydroiodic acid (55\%) were purchased from Sigma Aldrich, hydrochloric acid (35\%) from Daejung Chemicals (South Korea), hydrogen peroxide (30\%) from OCI Company Ltd. (South Korea), sulfuric acid (97\%) from PFP Osaka (Japan), and ammonium hydroxide (29\%) from Mallinckrodt Baker Inc. (NJ, USA), and were used as received. Transparent PET films were purchased from Saehan Industries (South 
Korea), and fused silica was purchased from Maicom Quartz GmbH (Germany). ITO coated PET was purchased from ione film (South Korea). All experiments and cleaning steps used the water from a Milli-Q Plus purification system (Millipore) with a resistivity of $18.2 \mathrm{M} \Omega \cdot \mathrm{cm}$.

Methods. Synthetic method of GO and preparation of PANi solution were described in our previous paper. ${ }^{6}$ Fused silica $\left(12 \times 45 \mathrm{~mm}^{2}\right)$, ITO $\left(15 \times 50 \mathrm{~mm}^{2}\right)$ and PET $(15 \times 50$ $\mathrm{mm}^{2}$ ) were used for LBL-assembly of the multilayer films composed of PANi/GO bilayers. Fused silica was cleaned by sonication in Piranha solution (sulfuric acid and hydrogen peroxide in $7: 3$ ration) at $70{ }^{\circ} \mathrm{C}$ for $1 \mathrm{~h}$, and followed by sonication in RCA solution (water, hydrogen peroxide, and ammonium hydroxide in 5:1:1 ratio) at $70{ }^{\circ} \mathrm{C}$ for $1 \mathrm{~h}$. In the case of ITO glass, the substrate cleaned by a successive rinsing in acetone, ethanol, and $\mathrm{H}_{2} \mathrm{O}$, was then dried under a gentle stream of nitrogen, and immersed into a freshly prepared piranha solution at RT just for $10 \mathrm{~s}$. PET substrates (cleaned by a successive rinsing in acetone, ethanol, and $\mathrm{H}_{2} \mathrm{O}$ ) were then dried under a gentle stream of nitrogen and cleaned using Digital UV ozone system (PSD Series, Novascan) for $1 \mathrm{~h}$ for the removal of molecular organic contaminations and simultaneously the oxygenated functionalization of the surface by the irradiation of intense ultraviolet light; thereby, the cleaned PET substrates were negatively-charged.

For LBL-assembly of multilayer films based on dip-coating technique, ${ }^{17}$ freshly cleaned substrates (fused silica, ITO and PET) were first immersed into a solution of positively charged PANi $(0.5 \mathrm{mM}, \mathrm{pH} 2.6)$ for $15 \mathrm{~min}$, and then washed in deionized water for $1 \mathrm{~min}$. The washing step was repeated for three times. Subsequently, the substrates were dried under a gentle stream of nitrogen gas. Again, the PANi coated substrates were immersed into a solution of negatively-charged $\mathrm{GO}(0.125 \mathrm{mg} / \mathrm{mL}, \mathrm{pH} 3.5)$ for $15 \mathrm{~min}$ to allow the deposition of the GO layer. The washing and drying steps as described above were followed. The LBL-assembly of PANi/GO bilayer on the substrate was repeated in a successive manner, until desired thickness of multilayer (PANi/GO) films was attained. The conversion of PANi/GO to $\mathrm{PANi} / \mathrm{RGO}$ layer pairs in the multilayer films was achieved during being exposed to $\mathrm{HI} / \mathrm{H}_{2} \mathrm{O}$ vapor at $100{ }^{\circ} \mathrm{C}$ over $3 \mathrm{~h}$. The LBL-assembly of PANi and GO onto a fused silica substrate was monitored using UV/visible spectrometer (Perkin Elmer, Lambda 40). The thickness of the multilayer film deposited on silicon wafers was measured using a realtime spectroscopic ellipsometer (EllipsoTechnology, ElliSE-F) with a Xe arc lamp (350-820 nm) equipped with a rotating polarizer, a liquid cell with optical access at an incidence angle of $60^{\circ}$, and a multichannel detection system. Employing a self-made computer program, the elliptical azimuth and phase angle were calculated for both the cleaned reference substrate and the multilayer films. Field emission scanning electron microscopy (FE-SEM) was carried out on a JSM-7001F SEM microscope at an accelerating voltage of $20 \mathrm{kV}$. The structural characteristics of the multilayer films were investigated using Raman spectrometer (Raman-LTPL) at $\lambda_{\mathrm{ex}}$ of $533 \mathrm{~nm}$. Elemental compositions of the multilayer films were analyzed using X-ray photoelectron spectroscopy microprobe (PHI 5000 VersaProbe II, monochromatic AlK $\alpha$ X-rays source). The resistance of the samples was measured using the four and two probe method on KEITHLEY-2400.

The electrochemical measurement of the electrodes composed of $30 \mathrm{PANi} / \mathrm{RGO}$ bilayers $\left(\mathrm{PANi}-\mathrm{RGO}_{30}\right.$ ) that were LBL-assembled on a non-conductive and flexible PET substrate (working electrode) were evaluated using cyclic voltammetry (CV), and galvanostatic charge/discharge measurement. The cell included platinum wire as the counter electrode and $\mathrm{Ag} / \mathrm{AgCl}$ as the reference electrode in $1 \mathrm{M} \mathrm{H}_{2} \mathrm{SO}_{4}$ electrolyte.

\section{Results and Discussion}

Preparation of PANi/GO Multilayer Films. The LBLassembly of GO and PANi layers was carried out on different solid substrates such as PET, indium tin oxide (ITO) and fused silica, according to our previous paper. ${ }^{6} \mathrm{The} \mathrm{pH}$ of the PANi solution that yielded optimal doping conditions was found to be 2.6. The $\mathrm{pH}$ of the washing solution and GO solution were also set to 2.6 and 3.5 , respectively, in order to minimize the transformation of the emeraldine salt into an emeraldine base. The deposition of PANi and GO on solid substrate PET was assessed based on the UV/visible absorbance. The deposition of up to alternating $15 \mathrm{PANi} / \mathrm{GO}$ bilayers was monitored by measuring the characteristic absorbance of the multilayer film at 550 and $830 \mathrm{~nm}$, respectively, as shown in Figure 1 (inset), indicating the regular deposition of PANi and GO on the PET substrate. It is noteworthy that the FE-SEM topographical images of the PANi/RGO multilayer film on PET substrate obtained via $\mathrm{HI} / \mathrm{H}_{2} \mathrm{O}$ vapor treatment at $100^{\circ} \mathrm{C}$ for $3 \mathrm{~h}$ (Figure S1), indicated no significant damage on the film surface.

Spectroscopic Studies of the Chemical Conversion from (PANi/GO) to (PANi/RGO) Films. GO in multilayer film composed of $30 \mathrm{PANi} / \mathrm{GO}$ bilayers (shorten to $\mathrm{PANi}-\mathrm{GO}_{30}$ )

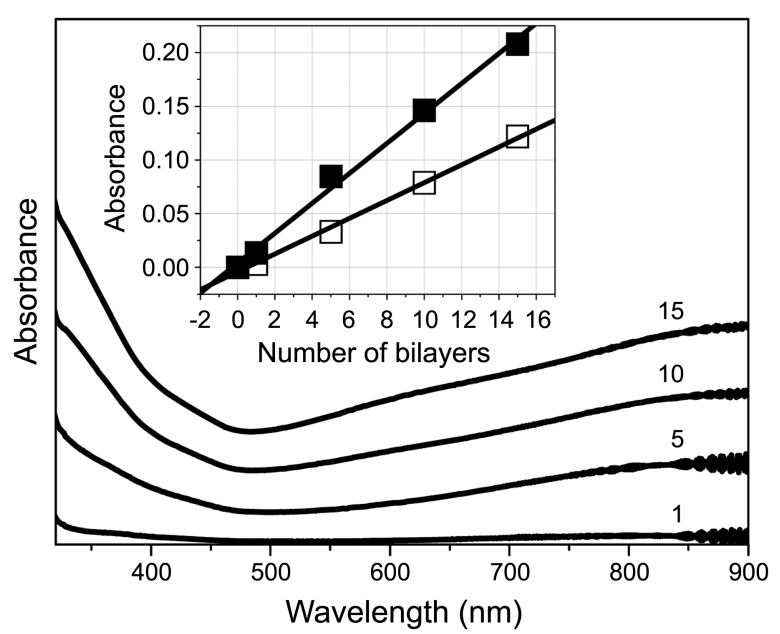

Figure 1. UV/visible absorption spectra of the multilayer films composed of different number of PANi/GO bilayers deposited onto a PET. Inset: Plot of the absorbance at 550 ( $\square$ ) and $830 \mathrm{~nm}$ (ש) $v s$. the number of the bilayers. 
was converted to $\mathrm{RGO}$, as being exposed on $\mathrm{HI} / \mathrm{H}_{2} \mathrm{O}$ vapor at $100{ }^{\circ} \mathrm{C}$ for $3 \mathrm{~h}$. The conversion from PANi/GO to PANi/ RGO in a multilayer film during the $\mathrm{HI} / \mathrm{H}_{2} \mathrm{O}$ vapor treatment was investigated using UV/visible, Raman, and XPS spectroscopy.

The UV/visible spectra of a PANi- $\mathrm{GO}_{30}$ multilayer film deposited onto a fused silica were compared before and after $\mathrm{HI} / \mathrm{H}_{2} \mathrm{O}$ vapor treatments, as shown in Figure 2. Note that $\mathrm{UV} /$ visible spectra of the pure GO and PANi films was also inserted in the supporting information (SI) for the references in the interpretation of overlapped absorbances of PANi$\mathrm{GO}_{30}$ film, as shown in Figure S2. The absorption peak at $232 \mathrm{~nm}$, assigned to the $\pi-\pi^{*}$ transition of GO, was redshifted to $280 \mathrm{~nm}$, indicating an increased $\pi$-conjugation length due to the restoration of the delocalized electron system through elimination of oxygenated functional groups including carbonyl, carboxyl, epoxide, and hydroxyl on the GO upon exposure to $\mathrm{HI} / \mathrm{H}_{2} \mathrm{O}$ vapor. ${ }^{18}$ The color of PANi$\mathrm{GO}_{30}$ films turned from blue to dark brown immediately after $\mathrm{HI} / \mathrm{H}_{2} \mathrm{O}$ vapor treatment (the digital images in insets of Figure 2), indicating the reduction of GO to RGO. The broad shoulder (290-350 nm) observed for GO was ascribed to the $\mathrm{n}-\pi^{*}$ transition of epoxide (C-O-C) and peroxide (R-O-O-R) in the GO. ${ }^{19}$ This broad shoulder was typically observed in solid-state GO thin films, indicating the presence of peroxidelike linkages (Figure S2a). The absorption at 200-500 nm was increased after the $\mathrm{HI} / \mathrm{H}_{2} \mathrm{O}$ vapor treatment, indicating the fact that conjugation (oxidation) state of pure PANi increased, while the absorption intensity in the range of 600 to $1100 \mathrm{~nm}$ was decreased due to slight reduction of doping state (Figure $\mathrm{S} 2 \mathrm{~b}$ ). The $\mathrm{HI} / \mathrm{H}_{2} \mathrm{O}$ vapor reduction seems to have no significant effect on a broad absorbance (600-1100 $\mathrm{nm}$ ) in the NIR region (centered at $\sim 880 \mathrm{~nm}$ ), which could be assigned to the dispersion of the polaron bands formed via overlap among the polarons of adjacent tetrameric units. ${ }^{20,21}$ The bands were known to be particularly sensitive to the geometric arrangement of the polymer backbone. It is noteworthy that the characteristic absorbance of emeraldine base at $550 \mathrm{~nm}$ was not observed from PANi/RGO film (Figure 2), indicating that PANi still remains in a doping state. The characteristic absorbance of PANi/GO $(310 \mathrm{~nm})$ was shifted to $400 \mathrm{~nm}$ after $\mathrm{HI} / \mathrm{H}_{2} \mathrm{O}$ vapor treatment. The spectral shift was ascribed to the formation of a chargetransfer complex between the both PANi and RGO electronrich components. The digital image of $\mathrm{PANi}^{-\mathrm{GO}_{30}}$ film on PET depicted in Figure 2 (insets) showed high flexibility and also transparency of the electrodes that decreased from 67 to $44 \%$ after $\mathrm{HI} / \mathrm{H}_{2} \mathrm{O}$ vapor treatment (Figure $\mathrm{S} 3$ ). The ellipsometric thickness of PANi-GO $\mathrm{GO}_{30}$ film was found to be $71.2 \pm 1.4 \mathrm{~nm}$. The thickness of the PANi-RGO ${ }_{30}$ film decreased by about $3 \%$ upon chemical reduction using $\mathrm{HI} /$ $\mathrm{H}_{2} \mathrm{O}$ vapor treatment and the ultimate thickness of PANi$\mathrm{RGO}_{30}$ film was $69.1 \pm 2.2 \mathrm{~nm}$.

The Raman spectra of PANi-RGO $\mathrm{RO}_{30} /$ fused silica film (Figure S4) illustrated the reduction from GO to RGO in the LBL-films during $\mathrm{HI} / \mathrm{H}_{2} \mathrm{O}$ vapor treatment. The $\mathrm{GO} / \mathrm{RGO}$ reduction in the multilayer assemblies was clearly identified

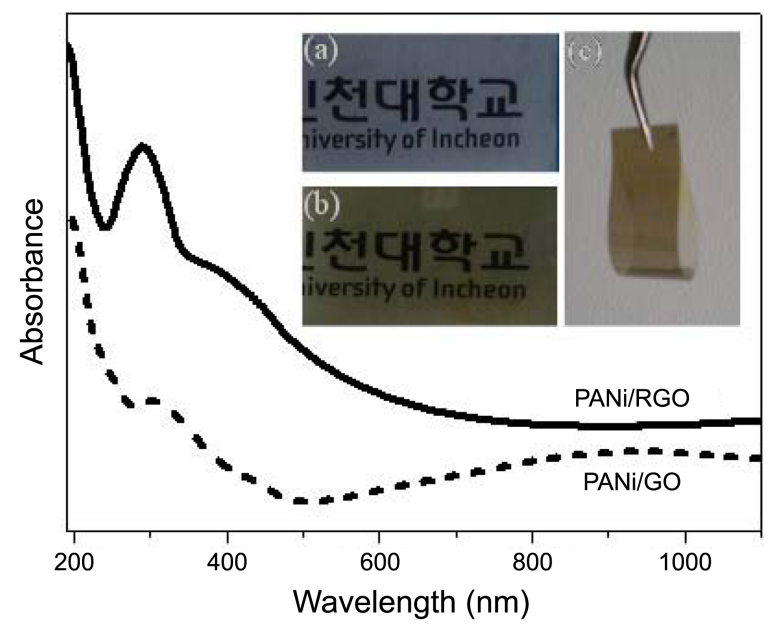

Figure 2. UV/visible absorption spectra of the multilayer films composed of PANi-GO $\mathrm{GO}_{30}$ film (dash), which was converted to PANi-RGO $\mathrm{RG}_{30}$ film by $\mathrm{HI} / \mathrm{H}_{2} \mathrm{O}$ vapor treatment at $100{ }^{\circ} \mathrm{C}$ (solid line). (Insets) The digital photo images of (a) PANi-GO $30 / \mathrm{PET}$, (b) PANi-RGO $30 /$ PET, and (c) Folded PANi-RGO ${ }_{30} /$ PET film.

by the increased $\mathrm{D} / \mathrm{G}$ intensity ratio (1.17) compared to the ratio of the virgin films $(0.90)$. The enhanced ratio of the $\mathrm{D} /$ $\mathrm{G}$ intensities resulted from the formation of more numerous new graphitic domains along with a decrease in the average size of the $s p^{2}$ domains upon reduction of the exfoliated GO.

The chemical compositions of the PANi-GO/PET analyzed using XPS were compared with those after the $\mathrm{HI} / \mathrm{H}_{2} \mathrm{O}$ vapor reduction, as shown in Figure 3. The composition of the multilayer films were calculated based on the areas of the XPS peaks, as listed in Table 1. High-resolution scan analysis of $\mathrm{C}, \mathrm{O}$, and $\mathrm{N}$ spectra (Figure 3(a)) allowed us to determine the composition of the virgin $\mathrm{PANi} / \mathrm{GO}$ multilayer film: $73.5 \% \mathrm{C} 1 \mathrm{~s}(284 \mathrm{eV}), 23.4 \% \mathrm{O} 1 \mathrm{~s}(532 \mathrm{eV}), 3.1 \% \mathrm{~N} 1 \mathrm{~s}(399$ $\mathrm{eV}$ ), which were changed to $81.6 \%, 8.9 \%$, and $7.6 \%$ after $\mathrm{HI} / \mathrm{H}_{2} \mathrm{O}$ vapor reduction, respectively. A distinctive feature of the composition analysis is the strong decrease in the oxygen content from 23.4 to $8.9 \%$ during the $\mathrm{HI} / \mathrm{H}_{2} \mathrm{O}$ vapor reduction, exhibiting considerable deoxygenation from GO layers. Besides, surface analysis was performed by fitting the XPS curve to a Gaussian-Lorentzian function after correction for Shirley background..$^{22}$ Deconvolution of C $1 \mathrm{~s}$ peak (Figure 3b) revealed four characteristic peaks of C-C/ $\mathrm{C}=\mathrm{C}(283.5 \mathrm{eV}), \mathrm{C}-\mathrm{O}(286.0 \mathrm{eV}), \mathrm{C}=\mathrm{O}(287.5 \mathrm{eV})$, and $\mathrm{O}-$ $\mathrm{C}=\mathrm{O}(289 \mathrm{eV})$, indicating the presence of oxygenated functional groups on the GO sheets. ${ }^{23}$ All oxygenated functional groups containing characteristic peaks of C-O $(286.0 \mathrm{eV})$, $\mathrm{C}=\mathrm{O}(287.5 \mathrm{eV})$, and $\mathrm{O}-\mathrm{C}=\mathrm{O}(289 \mathrm{eV})$ were decreased significantly after $\mathrm{HI} / \mathrm{H}_{2} \mathrm{O}$ vapor treatment (Figure 3(c)). Note that the $\mathrm{C}: \mathrm{O}$ ratio in the composition of $\mathrm{GO}$ were comparable to the literature values, ${ }^{24}$ despite batch-to-batch variability in the composition of functional groups in GO samples. The N1s core-level spectra (Figure 3(d) and 3(e)) revealed three peaks in the deconvolution of the spectra, which were corresponded to different electronic states: The benzenoid amine with a binding energy (BE) centered at $398.9 \mathrm{eV}$, the quinoid amine with a $\mathrm{BE}$ at $397.5 \mathrm{eV}$, and the 

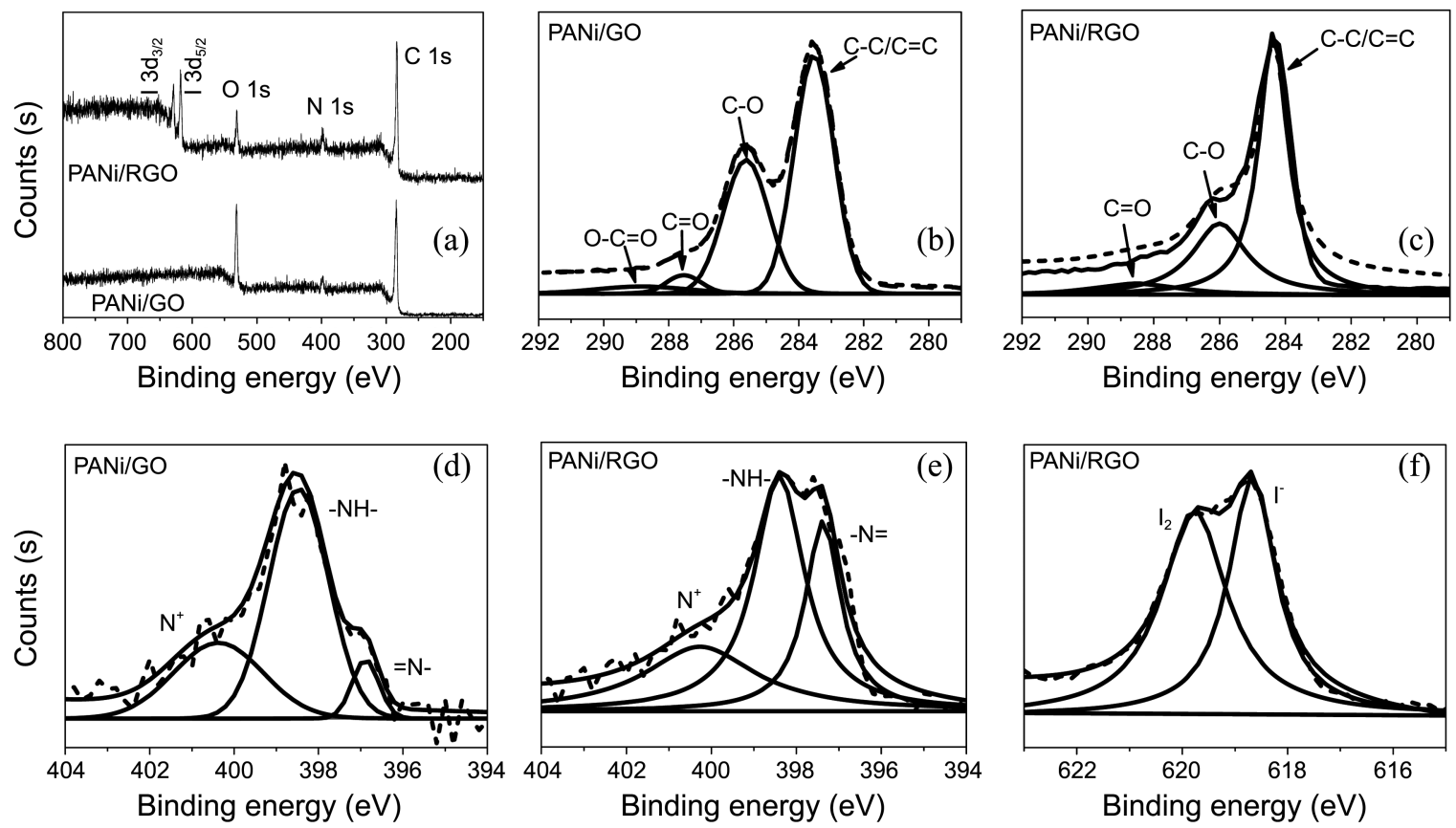

Figure 3. XPS spectra of the PANi/GO and PANi/RGO films. (a) Survey scan, (b, c) C 1s, (d, e) N 1s and (f) I 3d $\mathrm{d}_{5 / 2}$ spectra.

nitrogen cationic radical $\left(\mathrm{N}^{+}\right)$with a $\mathrm{BE}$ at $401.0 \mathrm{eV} .^{13}$ The benzenoid amine (-NH-) content decreased from 62.3 to $46.3 \%$, while the nitrogen quinoid amine $(-\mathrm{N}=)$ increased significantly from 7.1 to $27.0 \%$. The cationic radical $\left(\mathrm{N}^{+}\right)$ content also decreased slightly from 30.5 to $26.6 \%$ (Table 1 ). These observations indicate that the oxidation level of PANi in the multilayer films was strongly enhanced during HI/ $\mathrm{H}_{2} \mathrm{O}$ vapor reduction of the $\mathrm{PANi} / \mathrm{GO}$ films. It should be noted that trace amounts $(1.9 \%)$ of I was detected from the $\mathrm{PANi} / \mathrm{RGO}_{30}$ films. The iodine anions were expected to play an essential role to reduce GO and the formation of conjugated RGO. ${ }^{25}$ The $\mathrm{I} 3 \mathrm{~d}_{3 / 2}$ and $\mathrm{I} 3 \mathrm{~d}_{5 / 2}$ core-level spectra revealed two peaks in the deconvolution of the spectra, which were corresponded to different electronic states: the I $3 \mathrm{~d}_{3 / 2}$ with a binding energy (BE) centered at $630 \mathrm{eV}$ and the $\mathrm{I} 3 \mathrm{~d}_{5 / 2}$ with a $\mathrm{BE}$ at $619 \mathrm{eV}$ (Figure 3(a)). From the $\mathrm{d}_{5 / 2}$ peak, the iodine $\left(\mathrm{I}_{2}\right)$ and iodide ion $\left(\mathrm{I}^{-}\right)$content were found to be $53.4 \%$ and $46.5 \%$, respectively (Figure $3(\mathrm{f})$ ). These residual iodine anion $\left(\mathrm{I}^{-}\right)$and neutral iodine $\left(\mathrm{I}_{2}\right)$ acted as dopants in the conjugated PANi and RGO layers. ${ }^{25,26}$

Electrochemical Properties. The electrochemical performance of PANi-RGO ${ }_{30}$ electrodes LBL-assembled on a PET substrate (working electrode) were evaluated in a cell including a platinum wire (counter electrode) and an $\mathrm{Ag} /$ $\mathrm{AgCl}$ (reference electrode) in $1 \mathrm{M} \mathrm{H}_{2} \mathrm{SO}_{4}$ electrolyte with

Table 1. The composition (\%) of high resolution $\mathrm{C} 1 \mathrm{~s}$ and $\mathrm{N} 1 \mathrm{~s}$ peaks in XPS of the LBL-assembled PANi/GO and PANi/RGO films

\begin{tabular}{ccccc|ccc}
\hline \multirow{2}{*}{ Samples } & $\mathrm{C}-\mathrm{C}$ & $\mathrm{C}-\mathrm{O}$ & $\mathrm{C}=\mathrm{O}$ & $\mathrm{O}-\mathrm{C}=\mathrm{O}$ & $=\mathrm{N}-$ & $-\mathrm{NH}-$ & $\mathrm{N}^{+}$ \\
& 283.5 & 286 & 287.8 & 289.5 & 397.5 & 398.9 & 401.0 \\
\hline PANi/GO & 56.29 & 36.15 & 3.74 & 3.80 & 7.1 & 62.3 & 30.5 \\
PANi/RGO & 61.0 & 31.21 & 7.78 & - & 27.0 & 46.3 & 26.6 \\
\hline
\end{tabular}

using $\mathrm{CV}$, and galvanostatic charge/discharge measurements. By comparison, the evaluation measurements were also carried out for PANi-RGO $\mathrm{PG}_{30}$ on ITO-coated PET substrate (the current collector).

The average volumetric capacitance values, $C\left(\mathrm{~F} / \mathrm{cm}^{3}\right)$ of the electrodes were estimated based on the galvanostatic charge/discharge process, according to the following Eqs. (1), as summarized in Table 2.

$$
C=(I \cdot \Delta t) /(\Delta E \cdot V)
$$

where $I$ is the current loaded (A), $\Delta t$ is the discharge time (s), $\Delta E$ is the potential change during the discharge process (volt), and $V$ is the volume of the active material in electrode $\left(\mathrm{cm}^{3}\right)$.

Rate-dependent $\mathrm{CVs}$ for the PANi-RGO $\mathrm{R}_{30} / \mathrm{PET}$ electrode (Figures 4(a)) showed almost rectangular-shaped curve for all scan rates from 5 to $40 \mathrm{mV} / \mathrm{s}$ over potential range of $-0.2 \sim 0.8 \mathrm{~V}$, indicating the high conductivity of the electrode and the optimal capacitive behavior. Representative curves in the charge/discharge plot of the PANi-RGO $\mathrm{R}_{30} / \mathrm{PET}$ electrodes at current density from 3 to $20 \mathrm{~A} / \mathrm{cm}^{3}$ (Figure 4(b)) showed the near-triangular shape, indicating less mass transport resistance and good charge propagation of ions within the electrodes. The specific capacitance from charge/discharge curve of PANi-RGO $\mathrm{RG}_{30} / \mathrm{PET}$ electrode was found to be $529 \mathrm{~F} / \mathrm{cm}^{3}$ at current density $3 \mathrm{~A} / \mathrm{cm}^{3}$ (Table 2), which is one of the best values yet achieved among carbon based materials including conducting polymers listed in Table S1. The electrode potential in the discharge curve decreased exponentially in distinctive two stages of the potential drop; first sharply in the range of $0.8 \sim 0.5 \mathrm{~V}$ and then gently in the range of $0.50 \sim(-0.2) \mathrm{V}$. The former stage with relatively short discharge duration is ascribed to pure electric double layer (EDL) capacitance. The latter stage with much longer 

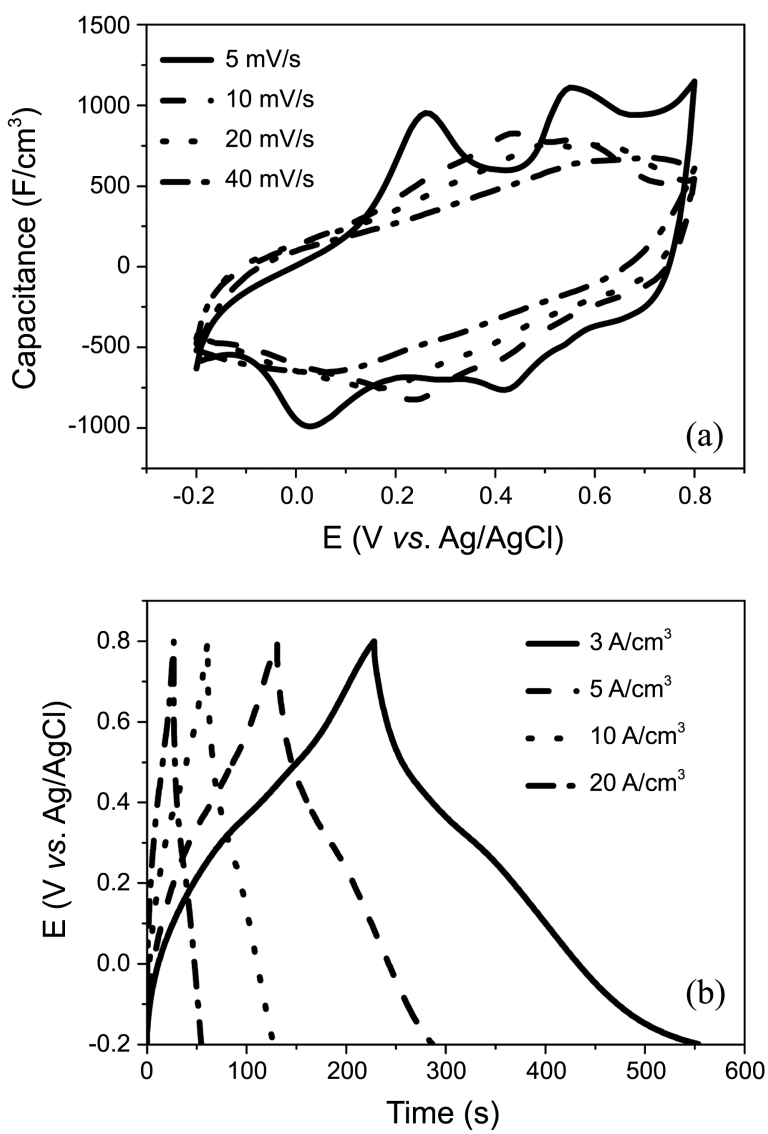

Figure 4. (a) Cyclic voltammograms at scan rate of 5-40 mV/s (b) Galvanostatic charge/discharge curves at current density of 3-20 $\mathrm{A} / \mathrm{cm}^{3}$ of PANi-RGO $\mathrm{P}_{30} / \mathrm{PET}$.

discharge duration was faradaic capacitance of the PANi component. $^{27}$ For instance, Zhiqiang Niu and co-workers observed a specific capacitance of $359 \mathrm{~F} / \mathrm{cm}^{3}$ at $5 \mathrm{mV} / \mathrm{s}$ with a flexible RGO electrode on PET substrate. ${ }^{28}$

Meanwhile, PANi-RGO $\mathrm{R}_{30} / \mathrm{ITO}$ showed no distinctive faradaic current peaks compared to $\mathrm{PANi}-\mathrm{RGO}_{30} / \mathrm{PET}$, but higher EDLC contribution to the CV (Figure S5). The different capacitive behavior was resulted mainly from higher conductivity of the current collector ITO compared to PET. The redox peaks in $\mathrm{CV}$ of PANi-RGO $\mathrm{R}_{30} / \mathrm{ITO}$ could not be clearly identified, because they were supposedly overlaid by the strong EDL capacitive current, which relies highly on conductivity of the electrode (Figure S5). The specific capacitance from charge/discharge curve of PANi-RGO $\mathrm{PO}_{30} / \mathrm{ITO} / \mathrm{PET}$ electrode was found to be $956 \mathrm{~F} / \mathrm{cm}^{3}$ (Table 2) which was higher than that of PANi-RGO ${ }_{30} / \mathrm{PET}$ electrode. The maximum volumetric capacitance of $\mathrm{PANi}-\mathrm{RGO}_{30} / \mathrm{PET}$ and PANi$\mathrm{RGO}_{30} / \mathrm{ITO}$ electrodes decreased exponentially as the current density increased, leading to the values of 136 and $416 \mathrm{~F} /$ $\mathrm{cm}^{3}$ at $70 \mathrm{~A} / \mathrm{cm}^{3}$, respectively (Table 2 ).

The durability of the electrode materials is extremely important for the long-term maintenance of supercapacitors. The maximum specific capacitance of the PANi-RGO ${ }_{30} / \mathrm{PET}$ electrode decreased gently even after 1000 charge/discharge cycles at a current density of $3 \mathrm{~A} / \mathrm{cm}^{3}$, compared to PANi$\mathrm{RGO}_{30} / \mathrm{ITO}(14$ vs. $21 \%$ ), as shown in Figure 5. The PANi-
Table 2. Volumetric capacitances calculated from charge/discharge curves of PANi-RGO ${ }_{30} / \mathrm{PET}$ and $\mathrm{PANi}-\mathrm{RGO}_{30} / \mathrm{ITO}$

\begin{tabular}{lccccccc}
\hline Current Density $\left(\mathrm{A} / \mathrm{cm}^{3}\right)$ & 3 & 5 & 10 & 20 & 30 & 50 & 70 \\
\hline Capacitance $\left(\mathrm{F} / \mathrm{cm}^{3}\right) / \mathrm{PET}$ & 529 & 422 & 358 & 299 & 264 & 199 & 136 \\
Capacitance $\left(\mathrm{F} / \mathrm{cm}^{3}\right) / \mathrm{ITO}$ & 956 & 783 & 662 & 573 & 526 & 461 & 416
\end{tabular}

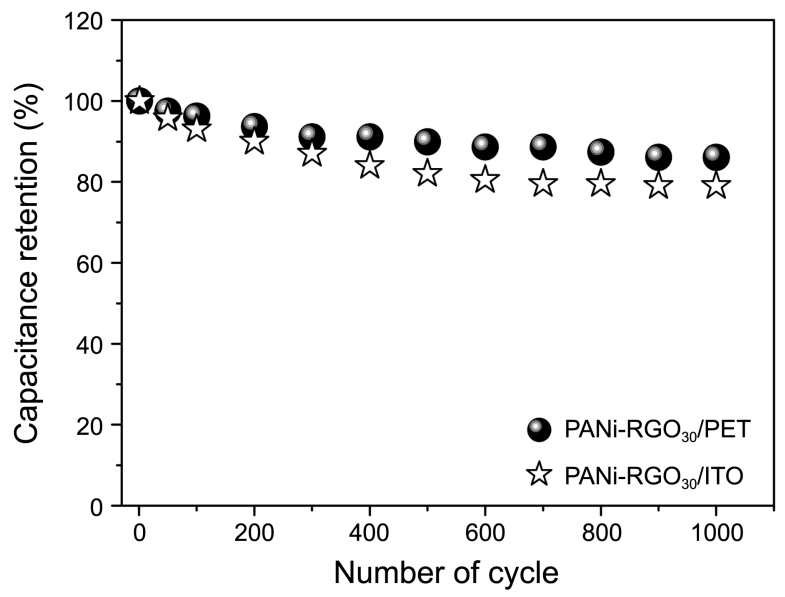

Figure 5. Cycle stability tests of PANi-RGO $\mathrm{RG}_{30} / \mathrm{PET}$ and PANi$\mathrm{RGO}_{30} / \mathrm{ITO}$ electrode.

$\mathrm{RGO}_{30} / \mathrm{PET}$ exhibited an excellent volumetric capacitance, good cycling stability, and rapid charge/discharge rates, which are required for supercapacitors. Furthermore, PANi/ GO and PANi/RGO films were strongly adhered on PET, so that the films could not be stripped off easily from the substrate even by applying mechanical force. By contrast, $\mathrm{PANi} / \mathrm{GO}$ and $\mathrm{PANi} / \mathrm{RGO}$ films were peeled off easily from ITO and fused silica.

Flexibility of PANi-RGO ${ }_{30}$ /PET Electrode. The combination of excellent mechanical flexibility and electric capacitive performance is the key to realizing flexible energy storage devices. ${ }^{29}$ Although constructing specific structural layouts and developing new electronic materials are conceptually different topics, they also offer complementary ways to achieve flexible electronics. ${ }^{30}$ The excellent electrical and mechanical properties of the organic PANi/RGO thin films and the unique network structure of PANi/RGO multilayer films would provide the composite electrode great potential use in flexible conductors; a key component of flexible and curvilinear large-area electronics such as sensory skins for robotics, structural health monitors, and wearable communication devices.

The electrical resistance of the PANi- $\mathrm{RGO}_{30} / \mathrm{PET}$ was determined as a function of the bending angle, and compared with that of ITO/PET electrode (Figure 6). The bend test was carried out using a home-made two-point bending device and a high-precision mechanical system. The electrical resistance of the PANi-RGO $\mathrm{R}_{30} / \mathrm{PET}$ was increased gently up to a bend radius of $2.2 \mathrm{~mm}$, and recovered to the initial value after straightening (Figure 6(a)). The PANi-RGO $\mathrm{P}_{30} / \mathrm{PET}$ electrode exhibited a weak tendency to increase in the resistance after the first three cycles. The electrical resistance 

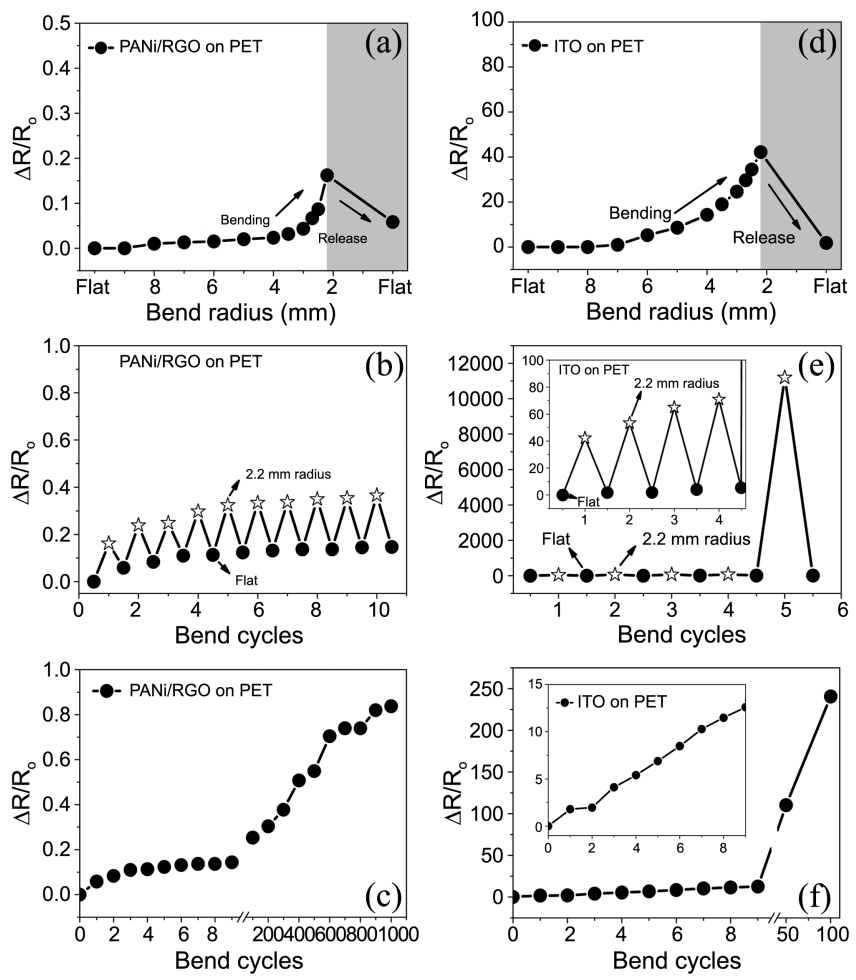

Figure 6. Electric resistance change of thin films under mechanical deformation. Electric resistance variation of thin films at a bend radius up to $2.2 \mathrm{~mm}$ in the first cycle (a) PANi-RGO $\mathrm{R}_{30} / \mathrm{PET}$, (d) ITO on PET. Electric resistance change of the films when bending to a radius of $2.2 \mathrm{~mm}$ and then straightening for each cycle (b) PANi-RGO SO $_{3} / \mathrm{PET}$, (e) ITO on PET. The resistance change of the films as a function of bend cycles for a bend radius of $2.2 \mathrm{~mm}$ (c) PANi-RGO $\mathrm{RO}_{30} / \mathrm{PET}$, (f) ITO on PET.

difference of the PANi-RGO $\mathrm{R}_{30} / \mathrm{PET}$ electrode per each bend/ straight cycle remains nearly unchanged within $20 \%$ (Figure $6(\mathrm{~b})$ ). The resistance of the PANi-RGO $\mathrm{R}_{30} / \mathrm{PET}$ tended to increase strongly after 200 bending cycles with a fixed bend radius of $2.2 \mathrm{~mm}$ (Figure 6(c)). Conventional current collectors in supercapacitors including metallic foils and thin films tend to possess poor mechanical robustness and elasticity despite higher electrical conductivity, ${ }^{29}$ which make them unsuitable for flexible conductors. For example, ITO on a flat PET sheet showed a low sheet resistance of $150 \mathrm{ohm}$, which, however, strongly increased upon slight bending (Figure 6(d) and 6(e)). The resistance of ITO/PET electrode increased about $200 \%$ even after 1 bending cycle (Figure $6(f))$. The ultimate flexibility of the PANi/RGO thin films increased by a factor of 225 compared with the ITO.

\section{Conclusion}

Highly stable PANi/GO thin films were deposited onto a plastic substrate using LBL electrostatic self-assembly method. The GO in PANi/GO thin films on PET substrate were reduced to $\mathrm{RGO}$ by $\mathrm{HI} / \mathrm{H}_{2} \mathrm{O}$ vapor treatment at $100{ }^{\circ} \mathrm{C}$, whereby PANi structure remained nearly unchanged except a little reduction of doping state. The Raman spectra of PANi-RGO ${ }_{30} /$ fused silica film (Figure S4) clearly identified the reduction from GO to RGO in the LBL-films during the $\mathrm{HI} / \mathrm{H}_{2} \mathrm{O}$ vapor treatment based on the increased $\mathrm{D} / \mathrm{G}$ intensity ratio (1.17) compared to the ratio of the virgin films (0.90). A distinctive feature of the composition analysis using XPS was the strong decrease in the oxygen content from $23.4 \%$ to $8.9 \%$ during the $\mathrm{HI} / \mathrm{H}_{2} \mathrm{O}$ vapor reduction process, exhibiting considerable deoxygenation from GO layers. The characteristic absorbance of PANi/GO at $310 \mathrm{~nm}$ was red-shifted to the longer wavelength of $400 \mathrm{~nm}$ in $\mathrm{UV} /$ visible spectra of $\mathrm{PANi} / \mathrm{RGO}$ multilayer film after $\mathrm{HI} / \mathrm{H}_{2} \mathrm{O}$ vapor treatment. The spectral shift was ascribed to the formation of a charge-transfer complex between the electronrich components; PANi and RGO.

The electrodes fabricated using ultrathin PANi/RGO films exhibited a specific capacitance of $529 \mathrm{~F} / \mathrm{cm}^{3}$ (at a current density of $3 \mathrm{~A} / \mathrm{cm}^{3}$ ), and achieved a new record value among carbon-based devices including conducting polymers on a flexible PET substrate.

Furthermore, the electrical resistance of the PANi-RGO $\mathrm{PG}_{30}$ PET electrodes remained nearly unchanged within $20 \%$ during 200 bending cycles with a fixed bend radius of 2.2 $\mathrm{mm}$, indicating the increase in their flexibility by a factor of 225 compared with the ITO/PET electrode. The PANi-RGO ${ }_{30} /$ PET capacitors exhibited an improved cycling stability (14 vs. $21 \%$ ) after 1000 charge/discharge cycles at a current density of $3 \mathrm{~A} / \mathrm{cm}^{3}$, compared to PANi-RGO $\mathrm{R}_{30} / \mathrm{ITO}$. In addition, $\mathrm{PANi} / \mathrm{GO}$ and $\mathrm{PANi} / \mathrm{RGO}$ films showed much stronger adhesive affinity on PET, compared to ITO surface. The LBLassembly method was shown to provide not only a tool to prepare well-organized homogeneous PANi/RGO composites, but also optimal oxidation state of PANi in the multilayer films for achieving excellent electronic conductivities. The results we achieved in this study demonstrated potential application of PANi-RGO/PET electrodes in flexible and foldable supercapacitors.

Acknowledgments. This research was partially supported by the Research Grant of Incheon National University in 2011.

\section{References}

1. Gwon, H.; Kim, H. S.; Lee, K. U.; Seo, D. H.; Park, Y. C.; Lee, Y. S.; Ahn, B. T.; Kang, K. Energy Environ. Sci. 2011, 4, 1277.

2. Clark, K.W.; Zhang, X. G.; Vlassiouk, I. V.; He, G. W.; Feenstra, R. M.; Li, A. P. ACS Nano 2013, 7, 7956.

3. Chen, S.; Brown, L.; Levendorf, M.; Cai, W.; Ju, S. Y.; Edgeworth, J.; Li, X.; Magnuson, C. W.; Velamakanni, A.; Piner, R. D.; Kang, J. Y.; Park, J.; Ruoff, R. S. ACS Nano 2011, 5, 1321.

4. Singh, B. P.; Nayak, S.; Nanda, K. K.; Jena, B. K.; Bhattacharjee, S.; Besra, L. D. Carbon 2013, 61, 47.

5. Scarpa, F.; Adhikari, S.; Phani, A. S. Nanotechnology 2009, 20, 065709.

6. Sarker, A. K.; Hong, J. D. Langmuir 2012, 28, 12637.

7. Sarker, A. K.; Hong, J. D. Colloids and Surfaces A: Physicochem. Eng. Aspects 2013, 436, 967.

8. Oliveira, H. P.; Sydlik, S. A.; Swager, T. M. J. Phys. Chem. C 2013, 117, 10270.

9. Alvi, F.; Ram, M. K.; Basnayaka, P.; Stefanakos, E.; Goswami, Y.; Hoff, A.; Kumar, A. ECS Trans. 2011, 35, 167. 
10. Wang, Y. G.; Li, H.Q.; Xia, Y. Y. Adv. Mater. 2006, 18, 2619.

11. Yan, J.; Wei, T.; Shao, B.; Fan, Z.; Qian, W.; Zhang, M.; Wei, F. Carbon 2010, 48, 487.

12. Zhang, K.; Zhang, L. L.; Zhao, X. S.; Wu, J. Chem. Mater. 2010, 22, 1392.

13. Feng, X. M.; Li, R. M.; Ma, Y. W.; Chen, R. F.; Shi, N. E.; Fan, Q. L. W. Adv. Funct. Mater. 2011, 21, 2989.

14. Zhang, S.; Zeng, M.; Xu, W.; Li, J.; Xu, J.; Wang, X. DaltonTrans. 2013, 42, 7854 .

15. Feng, X.; Yan, Z.; Chen, N.; Zhang, Y.; Liu, Z.; Ma, Y.; Yang, Z.; Hou, W. New J. Chem. 2013, 37, 2203.

16. Chen, W.; Rakhi, R. B.; Alsharref, H. N. Nanoscale 2013, 5, 4134.

17. Decher, G.; Hong, J. D. Ber. Bunsen-Ges. Phys. Chem. 1991, 95, 1430.

18. Li, D.; Müller, M. B.; Gilje, S.; Kaner, R. B.; Wallace, C. G. Nat. Nanotechnol. 2008, 3, 101.

19. Saxena, S.; Tyson, T. A.; Shukla, S.; Negusse, E.; Chen, H. Y.; Bai, J. M. Appl. Phys. Lett. 2011, 99, 013104.

20. Fu, Y.; Weiss, R. A. Synth. Met. 1997, 84, 129.
21. Liu, C.; Zhang, J.; Shi, G.; Chen, F. J. Appl. Polym. Sci. 2004, 92, 171.

22. Yang, D. X.; Velamakanni, A.; Bozoklu, G.; Park, S. J.; Stoller, M.; Piner, R. D.; Stankovich, S.; Jung, I. H.; Field, D. A.; Ventrice, C. A., Jr.; Ruoff, R. S. Carbon 2009, 47, 145.

23. Mattevi, C.; Eda, G.; Agnoli, S.; Miller, S.; Mkhoyan, K. A.; Celik, O.; Mastrogiovanni, D.; Granozzi, G.; Garfunkel, E.; Chhowalla, M. Adv. Funct. Mater. 2009, 19, 2577.

24. Byon, H. R.; Lee, S. W.; Chen, S.; Hammond, P. T.; Horn, Y. S. Carbon 2011, 49, 457.

25. Pei, S. F.; Zhao, J. P.; Du, J. H.; Ren, W. C.; Cheng, H. M. Carbon 2010, 48, 4466.

26. Sharma, S. N. Mater. Chem. Phys. 2006, 100, 345.

27. Wu, Q.; Xu, Y.; Yao, Z.; Liu, A.; Shi, G. ACS Nano 2010, 4, 1963.

28. Niu, Z.; Zhang, L.; Liu, L.; Zhu, B.; Dong, H.; Chen, X. D. Adv. Mater. 2013, 25, 4035.

29. Sekitani, T.; Noguchi, Y.; Hata, K.; Fukushima, T.; Aida, T.; Someya, T. Science 2008, 321, 1468.

30. Rogers, J. A.; Someya, T.; Huang, Y. G. Science 2010, 327, 1603. 